УДК 81 '272

DOI 10.18413/2712-7451-2020-39-1-83-89

\title{
ПРОБЛЕМЫ АВТОХТОННЫХ ЯЗЫКОВ В ЗАПАДНОЙ АФРИКЕ (НА ПРИМЕРЕ КАМЕРУНА И НИГЕРИИ)
}

\section{PROBLEMS OF INDIGENOUS LANGUAGES IN WEST AFRICA (ILLUSTRATED BY CAMEROON AND NIGERIA)}

\author{
Ю.С. Блажевич \\ Yu.S. Blazhevich \\ Белгородский государственный национальный исследовательский университет, \\ Россия, 308015, г. Белгород, ул. Победы, 85 \\ Belgorod National Research University, \\ 85 Pobeda St, Belgorod, 308015, Russia \\ E-mail: blazhevich@bsu.edu.ru
}

\begin{abstract}
Аннотация
Отличительной особенностью Африки является высокая степень языкового и культурного разнообразия. В многоязычном и диглоссном обществе многочисленные миноритарные языки подвергаются опасности исчезновения, что ведет к обеднению всемирного культурного наследия. В этой связи возникла необходимость комплексного изучения специфики языковой ситуации для того, чтобы обозначить существующие проблемы, выявить их причины и наметить пути решения. Камерун и Нигерия выбраны для изучения существующих социолингвистических проблем в связи с тем, что их объединяет общее колониальное прошлое, а также схожие социолингвистические условия. Авторами дан анализ различных факторов экстралингвистического характера, представляющих угрозу для местных языков. Описаны лингвистические признаки умирания языка. Также выявлена проблема разделения языковых коллективов в результате искусственного насаждения границ в колониальных период, которое приводит к языковой диалектизации. Сформулированы необходимые условия для решения существующих проблем. Обнаружена зависимость витальности языка от наличия письменности и орфографической нормы, а также уровня функциональной нагрузки и жизнеспособности языка от его престижа в обществе. Обозначена роль языковой политики государства в создании условий, необходимых для повышения витальности языков, находящихся под угрозой исчезновения, путем увеличения их функциональной нагрузки.
\end{abstract}

\begin{abstract}
A distinctive feature of Africa is its high degree of linguistic and cultural diversity. In a multilingual and digloss society, numerous minority languages are at risk of disappearing, which leads to the impoverishment of the world cultural heritage. In this regard, there is a need for a comprehensive study of the specifics of the language situation in order to identify existing problems, identify their causes and identify solutions. Cameroon and Nigeria were chosen to study existing sociolinguistic problems because they share a common colonial past, as well as similar sociolinguistic conditions. The authors give an analysis of the various factors of extralinguistic nature, posing a threat to local languages. Linguistic signs of language dying are described. The problem of division of language collectives as a result of artificial planting of borders in the colonial period, which leads to language dialectization, is also revealed. The study reveals the dependence of the vitality of a language on the existence of a writing system and grammar. The dependence of the level of functional load and viability of the language on its prestige in society has also been shown. The important role of the national language policy in creating the conditions necessary to increase the vitality of the endangered languages by increasing their functional load has been discussed.
\end{abstract}


Ключевые слова: мультилингвизм, языковая политика, миноритарные языки, автохтонные языки, гибель языков, Камерун, Нигерия, Западная Африка.

Keywords: multilingualism, language policy, minority languages, indigenous languages, language death, Cameroon, Nigeria, West Africa

\section{Введение}

Африка славится богатым языковым и культурным разнообразием, что дает возможность наблюдать за многими явлениями, связанными с взаимодействием языков и культур. Наибольший интерес в плане языкового разнообразия представляют собой Нигерия и Камерун. Оба государства расположены в Западной Африке, разделяют общую границу и историю. На суммарной территории данных стран сконцентрированы приблизительно 700-800 языков, что составляет около 12 \% всех языков мира [Connel, 1998].

В этой ситуации монолингвизм становится очень редким явлением, ведь для успешной коммуникации житель многонациональной африканской страны, помимо родного языка, должен знать государственный язык и, как правило, наиболее распространенный язык межэтнического общения своего региона проживания. Таким образом, языковой репертуар африканцев зачастую состоит из европейского языка, а иногда и двух (языков бывших колониальных держав), автохтонного языка межэтнического общения и родного языка говорящего.

Несмотря на то, что языковое и культурное разнообразие Африки поражает воображение, многие языки находятся под реальной угрозой исчезновения. Организация ЮНЕСКО разработала Атлас языков мира, находящихся под угрозой вымирания, в котором все языки классифицированы по шкале от «находящихся в безопасности» до «вымерших». Благодаря этому источнику становится понятно, что каждый год категорию «вымерших» пополняют и языки Африки, а вместе с ними исчезают и культуры проживающих на территории Африки народов ${ }^{1}$.

Гибель языков может также означать исчезновение культур. Поскольку языки составляют часть мирового культурного наследия, задача их сохранения и витализации является важной и актуальной для всего мирового сообщества.

Целью данного исследования является описание и анализ специфики языковой ситуации, связанной с существующими проблемами местных камерунских и нигерийских языков. Для этого используется индуктивно-дедуктивный метод для осмысления и обобщения соответствующего теоретического и практического материала, а также сравнительно-сопоставительный метод, например, для анализа типов языковых ситуаций.

\section{Причины снижения витальности автохтонных языков Нигерии и Камеруна}

Анализ публикаций на тему исчезающих языков показывает, что при изучении причин «гибели» языков одни исследователи занимаются выяснением социальных, экономических и иных экстралингвистических факторов, других интересуют сугубо структурные изменения в языках, находящихся под угрозой. По нашему мнению, при серьезном междисциплинарном исследовании важно учитывать оба подхода.

Классификации факторов, приводящих к гибели языков разнятся, но большинство исследователей [Batibo, 2005, 2008; Багана и др., 2014; Dressler, 2017] сходятся во мнении, что основными причинами являются следующие:

1 UNESCO Atlas of the World's Languages in Danger. Available at: http://www.unesco.org/languages-atlas/ (accessed 11.10.2019). 
- уменьшение численности населения в результате гибели от болезней, природных катастроф, геноцида и военных конфликтов;

- расселение и миграции населения по различным социальным и экономическим причинам;

- урбанизация, при которой ребенок в качестве первого языка усваивает язык межэтнического общения в многоэтничной среде города, а родным языком может владеть на примитивном уровне; телей;

- смешанные браки, при которых ребенок усваивает язык только одного из роди-

- низкий статус языка в обществе, при котором снижение престижа этнического языка приводит к отказу от его употребления.

Как следует из данных факторов, ухудшение витальности языка связано с уменьшением количества его носителей как по причине их физической гибели, так и по причинам «оставления» языка или его «непередачи» следующему поколению.

Урбанизация наносит серьезный урон этническим языкам, поскольку многоязычие в городе требует использования государственного языка или языка межэтнического общения, отодвигая родной язык в сферу семейно-бытового общения [Simons \& Lewis, 2013, p. 18].

Судя по всему, именно сохранившиеся традиции и уклад жизни замкнутых общин сельской местности обеспечивают передачу этнических языков от поколения к поколению, а значит и их сохранение. Важно, что языки в таких условиях сохраняют свою целостность, богатство и колорит, отражаемые в неповторимых фольклорных традициях. По сравнению с обедневшим языком рожденных в городах, речь такого носителя не ограничивается базовым набором фраз, а характеризуется умелым использованием более сложных оборотов и фразеологических выражений.

В многоязычном обществе мажоритарный язык может, например, обслуживать все сферы жизнедеятельности языкового коллектива, оставляя за этническими языками лишь семейно-бытовую сферу. Иногда использование родного языка происходит лишь при проводимых обрядах и ритуалах. Процесс такого значительного снижения функциональной нагрузки J. Fishman [1987] называет «фольклоризацией» языка. Оценку функциональной нагрузки можно проводить для определения миноритарных языков. Чем меньше сфер охватывает язык, тем меньшей является его функциональная нагрузка [Dorian, 1982].

Сужение сфер употребления языка влечет за собой потерю той части лексики, которая перестает употребляться, ведь она больше не нужна, поскольку разговор на эту тему ведется на другом языке. Происходят также значительные упрощения в области грамматики и синтаксиса [Crystal, 1985; 2000].

Основными языковыми показателями разрушения языка можно считать множественные заимствования из доминирующего языка, агрессивно вытесняющие исконную лексику, а также потерю продуктивности словообразовательных моделей, поскольку слова можно не создавать, а просто заимствовать из другого, престижного, языка [Dressler, 1982]. Важно отметить, что, когда язык претерпевает такие серьезные негативные изменения, его носитель начинает еще больше ощущать «ущербность» и без того «непрестижного» в его представлении языка, происходит еще более сильная деградация языка, а в конечном итоге и отказ от его употребления.

\section{Способы повышения витальности автохтонных языков Нигерии и Камеруна}

Разорвать такой «замкнутый круг» способна продуманная языковая политика, повышающая престиж и функциональную нагрузку местных языков. Так, язык можно буквально «воскресить», если стимулировать его использование в обществе, например, в школьном обучении, на работе, в театре и других общественных местах [Fishman, $1977 ; 1991 ; 2002]$. 
Еще одним важным условием для сохранения языков является наличие письменности и орфографической нормы. По различным оценкам около 80 \% африканских языков не имеют унифицированных орфографических правил, что делает сложным их эффективное использование в учебном процессе [Adegbija, 2001], некоторые языки до сих остаются бесписьменными.

Разработка письменности многочисленных языков остается важнейшей задачей, так как именно письменность значительно повышает витальность языков, расширяет сферы их использования, дает возможность их изучения в школах и университетах. Так, например, в Камеруне с 1970 года существует программа, благодаря которой письменность получили многие африканские языки. Наиболее известным проектом по изучению языков является проект PROPELCA (Programme de Recherche Opérationeelle pour l'Enseignement des Langues au Cameroun), в рамках которого ведется обучение детей родному языку с начальной школы (помимо изучения одного из официальных языков), а в старших классах для изучения добавляется еще один язык [Romaine, 2002; Rosendal, 2008]. «Трилингвальная» модель обучения как нельзя лучше отвечает потребностям африканцев, проживающих в многонациональном государстве, поскольку именно «трилингвизм» характеризует функциональное распределение языков в репертуаре среднестатистического африканца в многоязычном государстве. Такое распределение языков обычно выглядит как иерархия, где на первом (по престижности) месте, находится официальный язык, на втором - наиболее распространенный для данного региона язык межэтнического общения и на последнем месте - язык внутриэтнического общения (родной язык). Данная схема может меняться в зависимости от конкретных социолингвистических условий многоязычного общества. В любом случае, социолингвистическую ситуацию в Африке можно охарактеризовать как «мультилингвальную».

\section{Государственные границы как причина языковой дивергенции}

Как уже было отмечено, Камерун и Нигерия имеют общую границу и разделяют общую колониальную историю. Современный этап существующих между ними отношений омрачился территориальным спором по поводу полуострова Бакасси в Гвинейском заливе, в результате которого полуостров отошел Камеруну.

B XIX веке на Африканском континенте страны-колонизаторы установили границы без учета особенностей существовавшего на тот момент социального и политического устройства, в результате чего многие племенные образования оказались оторванными друг от друга искусственно навязанными границами. Например, город Керева и одна часть племени мандара оказались на территории французской части Камеруна, а другая в Северной Нигерии. После разделения племя, перемещенное за границу, отрывалось от своих корней и получало другое название. По сути, одним и тем же народом являются, например, хиги в Нигерии и отделенные от него капсики, а также к одному племени принадлежат матакам и вула [Kamwendo, 2003]. До сих пор скрытый протест по поводу насильственного разделения этнических групп проявляется в незаконных пересечениях границ между соседствующими государствами. Жители приграничных районов при прохождении постов могут жульничать, так один и тот же человек может называть себя камерунцем или нигерийцем в зависимости от того, что ему выгодно в данный момент.

В настоящий момент, по данным энциклопедии «Этнолог», более 30 языков распространены как в Камеруне, так и в Нигерии [Simons, Fennig, 2019]. Это языки афаде, алеге, бата, битаре, дзодинка, эфай, эйагам (он же экин ква, ква, аква, абаква), эвант, фульфульде (фула), фум, главда, гуде, гвоко, хауса, хиде, канури, кутеп и многие другие. После отхождения полуострова Бакасси Камеруну, эфик также пополнил список языков, на которых говорят в обеих странах [Edung, 2015]. На языках это отражается в виде диа- 
лектизации, когда при недостатке общения между группами носителей язык каждой из разделенных групп развивается своим путем. В качестве примера могут служить диалекты языка фульфульде в Сенегале, Нигерии и Камеруне. В каждой из этих стран приняты собственные орфографические нормы, что значительно затрудняет взаимопонимание между носителями данных языков при письменном общении.

В перспективе происходящие изменения на различных языковых уровнях могут приводить к языковой дивергенции и возникновению новых отдельных друг от друга языков [Kamwendo, 2003].

\section{Заключение}

Языковая ситуация в исследуемом регионе характеризуется доминированием бывших колониальных языков в самых важных сферах жизни общества в ущерб этническим языкам. Как правило, европейский язык обладает наивысшим социолингвистическим статусом, за ним следует язык-посредник, обеспечивающий общение между различными этническими группами, на последнем месте остаются языки, используемые лишь для внутриэтнического общения. Это позволяет говорить о существовании триглоссии.

Языки, обладающие низким языковым статусом, подвергаются опасности вымирания, поскольку ухудшение их витальности связано не только с уменьшением количества носителей, но и с «оставлением» языка или его «непередачей» следующему поколению в связи с его низким социальным статусом в существующей иерархии. Решением может стать серьезная языковая политика, повышающая престиж и функциональную нагрузку местных языков.

Проблема искусственных границ в Африке привела к насильственному разделению этнических групп. Это в свою очередь, угрожает процессом языковой диалектизации, при которой в изоляции от основного языкового коллектива язык разделенной группы развивается собственным путем, все сильнее удаляясь от «оригинала». Для решения этих проблем предлагается установить общие орфографические нормы для одного и того же языка, используемого на территории соседних государств, составить словари, унифицировать грамматические нормы таких языков, а также разработать протокол взаимодействия по вопросам культурного сотрудничества данных стран.

Таким образом, проведенное исследование обозначило ряд проблем, обусловленных историческими, политическими, социологическими, культурными и иными аспектами сложившейся социолингвистической ситуации. В результате проведенного анализа предложены меры для повышения витальности автохтонных языков в данном регионе. Сделанные выводы дают возможность расширить представление о существующей ситуации и могут служить базой для дальнейших исследований в области африканистики и социолингвистики.

\section{Список литературы}

1. Багана Ж., Хапилина Е.В., Блажевич Ю.С. 2014. Английские заимствования в территориальных вариантах французского языка Африки. М., ИНФРА-М: 106 с.

2. Adegbija E. 2001. Saving threatened languages in Africa: A case study of Oko. Ed.: J.A. Fishman. Clevedon, Multilingual matters: 284-308.

3. Batibo H. M. 2005. Language Decline and Death in Africa: Causes, Consequences and Challenges. Clevedon, Buffalo, Toronto, Multilingual Matters Ltd., 181 p.

4. Batibo H. M. 2008. Poverty as a Crucial Factor in Language Maintenance and Language Death: Case Studies from Africa. In: Language and Poverty. Ed.: W. Harbert, S. McConnell-Ginet, et al. Bristol, Buffalo, Toronto, Multilingual Matters Ltd: 23-36.

5. Connell B. 1998. Moribund Languages of the Nigeria-Cameroon Borderland. In: Endangered Languages in Africa. Ed.: M. Brenzinger. Cologne, Rüdiger Köppe: 207-225. 
6. Crystal D. 1985. Dictionary of Linguistics and Phonetics. Oxford, Basil Blackwell, $337 \mathrm{p}$.

7. Crystal D.A. 2000. Language Death. Cambridge, Cambridge University Press, 198 p.

8. Dorian N. C. 1982. Language loss and maintenance in language contact situations. In: The Loss of Language Skills. Ed.: R. D. Lambert and B. F. Freed. Rowley, Newbury House: 44-59.

9. Dressler W.U. 1982. Acceleration, retardation, and reversal in language decay? In: Language Spread: Studies in Diffusion and Social Change. Ed.: R.L. Cooper. Bloomington, Indiana University Press: 321-336.

10. Dressler W.U. 2017. Independent, Dependent and Interdependent Variables in Language Decay and Language Death. European Review, 26 (1): 120-129.

11. Edung M.T.U. 2015. The Culturo-Linguistic Factor as a Facilitator of Peace in Present-Day Nigeria - Cameroun Border Relations. Journal of Language and Communication, 2 (2): 50-64.

12. Fishman J.A. 1977. The spread of English as a new perspective for the study language maintenance and language shift. In: The spread of English: The International Sociology of English as an Additional Language. Ed.: J.A. Fishman, R.A. Cooper et al. (ed.). Rowley, Newbury House: 108-135.

13. Fishman J.A. 1987. Language spread and language policy for endangered languages. In: Proceedings of the Georgetown University Roundtable on Language and Linguistics. Washington Georgetown University Press: 1-15.

14. Fishman J.A. 1991. Reversing Language Shift. Clevedon. UK, Multilingual Matters, 431 p.

15. Kamwendo G. 2003. On Cross-Border Languages and Cross-Border Collaboration between Malawi and Mozambique. Portuguese literary and cultural studies. Reevaluating Mozambique, 10: 87-103.

16. Romaine S. 2002. The Impact of Language Policy on Endangered Languages. International Journal on Multicultural Societies (IJMS), 4 (2): 94-212.

17. Rosendal T. 2008. Multilingual Cameroon Policy, Practice, Problems and Solutions. Gothenburg Africana Informal Series, 7: $65 \mathrm{p}$.

18. Simons G.F., Fennig C. D. Ethnologue: Languages of the World. Available at: https://www.ethnologue.com/country/CM (accessed: 11.10.2019).

19. Simons G.F., Lewis M.P. 2013. The world's languages in crisis. A 20-year update. In: Responses to Language Endangerment: In honor of Mickey Noonan. Eds:. E. Mihas et Al. John Benjamins Publishing company. Amsterdam / Philadelphia: 3-20.

\section{References}

1. Baghana J., Khapilina E.V., Blazhevich Yu.S. 2014. Angliyskie zaimstvovaniya $\mathrm{v}$ territorial'nykh variantakh frantsuzskogo yazyka Afriki [English borrowings in territorial variants of the French language in Africa]. M., INFRA-M: 106 p.

2. Adegbija E. 2001. Saving threatened languages in Africa: A case study of Oko. Ed.: J.A. Fishman. Clevedon, Multilingual matters: 284-308.

3. Batibo H. M. 2005. Language Decline and Death in Africa: Causes, Consequences and Challenges. Clevedon, Buffalo, Toronto, Multilingual Matters Ltd., 181 p.

4. Batibo H. M. 2008. Poverty as a Crucial Factor in Language Maintenance and Language

Death: Case Studies from Africa. In: Language and Poverty. Ed.: W. Harbert, S. McConnell-Ginet, et al. Bristol, Buffalo, Toronto, Multilingual Matters Ltd: 23-36.

5. Connell B. 1998. Moribund Languages of the Nigeria-Cameroon Borderland. In: Endangered Languages in Africa. Ed.: M. Brenzinger. Cologne, Rüdiger Köppe: 207-225.

6. Crystal D. 1985. Dictionary of Linguistics and Phonetics. Oxford, Basil Blackwell, 337 p.

7. Crystal D.A. 2000. Language Death. Cambridge, Cambridge University Press, 198 p.

8. Dorian N. C. 1982. Language loss and maintenance in language contact situations. In: The Loss of Language Skills. Ed.: R. D. Lambert and B. F. Freed. Rowley, Newbury House: 44-59.

9. Dressler W.U. 1982. Acceleration, retardation, and reversal in language decay? In: Language Spread: Studies in Diffusion and Social Change. Ed.: R.L. Cooper. Bloomington, Indiana University Press: 321-336.

10. Dressler W.U. 2017. Independent, Dependent and Interdependent Variables in Language Decay and Language Death. European Review, 26 (1): 120-129.

11. Edung M.T.U. 2015. The Culturo-Linguistic Factor as a Facilitator of Peace in Present-Day Nigeria - Cameroun Border Relations. Journal of Language and Communication, 2 (2): 50-64. 
12. Fishman J.A. 1977. The spread of English as a new perspective for the study language maintenance and language shift. In: The spread of English: The International Sociology of English as an Additional Language. Ed.: J.A. Fishman, R.A. Cooper et al. (ed.). Rowley, Newbury House: 108-135.

13. Fishman J.A. 1987. Language spread and language policy for endangered languages. In: Proceedings of the Georgetown University Roundtable on Language and Linguistics. Washington Georgetown University Press: 1-15.

14. Fishman J.A. 1991. Reversing Language Shift. Clevedon. UK, Multilingual Matters, 431 p.

15. Kamwendo G. 2003. On Cross-Border Languages and Cross-Border Collaboration between Malawi and Mozambique. Portuguese literary and cultural studies. Reevaluating Mozambique, 10: 87-103.

16. Romaine S. 2002. The Impact of Language Policy on Endangered Languages. International Journal on Multicultural Societies (IJMS), 4 (2): 94-212.

17. Rosendal T. 2008. Multilingual Cameroon Policy, Practice, Problems and Solutions. Gothenburg Africana Informal Series, 7: $65 \mathrm{p}$.

18. Simons G.F., Fennig C. D. Ethnologue: Languages of the World. Available at: https://www.ethnologue.com/country/CM (accessed: 11.10.2019).

19. Simons G.F., Lewis M.P. 2013. The world's languages in crisis. A 20-year update. In: Responses to Language Endangerment: In honor of Mickey Noonan. Eds:. E. Mihas et Al. John Benjamins Publishing company. Amsterdam / Philadelphia: 3-20.

\section{Ссылка для цитирования статьи For citation}

Блажевич Ю.С. 2020. Проблемы автохтонных языков в Западной Африке (на примере Камеруна и Нигерии). Вопросы журналистики, педагогики, языкознания. 39 (1): 83-89.

DOI: $10.18413 / 2712-7451-2020-39-1-83-89$

Blazhevich Yu.S. 2020. Problems of indigenous languages in West Africa (illustrated by Cameroon and Nigeria). Issues in Journalism, Education, Linguistics. 39 (1): 83-89. (in Russian). DOI:10.18413/2712-7451 2020-39-1-83-89 